\title{
The City in the Age of Remix
}

\author{
ALINA NAZMEEVA
}

Research Associate, Massachusetts Institute of Technology

\begin{abstract}
As a method of cultural production and communication, remix has permeated the way the social space is perceived, conceived of and lived. Physical social space is captured, constructed and mediated with digital tools and by a multitude of users. The explosive use of cultural software and social media is actively shaping the experience of architectural and urban space. Smart city movement proponents advocate for a kind of participatory decision-making in cities that is akin to digital social space dynamics. Within the architectural practice, the space is first produced as a digital remix. The social space, both online or offline, physical or digital, crowdsourced or expertdesigned, is socially produced as a collective assemblage of the fragments of digital images.
\end{abstract}

This essay aims to outline four trajectories by which physical (architectural and urban) social space is intertwined and remixed with digital (social media and the web) social space, and the broader implications of such cross-hatchings. Additionally, this paper aims to bring this term to architectural and urban discourse. Positing that remix has become the dominant model of spatial production in the contemporary world, what are the implications of it for the social space and for the public?

\section{INTRODUCTION}

The term remix is often used as a shorthand to describe a combination/composition of preexisting cultural objects that becomes a new cultural object. Remix culture, then, can be loosely defined as a society that enables combining or editing existing expressions, products, materials, to produce a new creative work. In the context of remix culture, a cultural object's characteristics are defined by its remixability: ${ }^{1}$ it is never static or complete; it is prone to be recorded or sampled; it is modular or ready to be divided into parts. Today, the term remix, which originated from multitrack recording and compositing in music, refers to the reworking of any cultural or media material. This broader understanding of remix took off in cultural discourse with the proliferation of the web, cultural software and social media, which reinvigorated remix culture into a broader range of cultural domains.

Remix is rarely used when speaking about cities and architecture. Yet throughout the centuries they have been created of salvaged materials or as palimpsests, ${ }^{2}$ remaking and retracing existing layouts of buildings and streets, repurposing existing parts to create new spaces, purposes and meanings. 
Both architecture and city are products of collective effort, heterogeneous combinations of materials, ideas and artifacts, intentional and accidental compositions of spaces, forms, ideologies and desires.

Nonetheless, the term remix proves immensely useful when speaking of social space - the notion that resists the categorical dichotomy of the physical and the digital. Colloquially, the concept of social space used to be linked to physical space - it was a plaza, public garden, coffee shop, parlor, club. Today, these social spaces are supplemented by and intertwined with social media, sharing platforms, online forums, massively multiplayer videogames and virtual worlds. Parents' garages, coffee shops and skate parks for teenagers are complemented with the likes of Fortnite and Minecraft, offices and conference centers with GTA, Zoom and Red Dead Redemption. ${ }^{3}$

It seems that remix has become a prevalent method of production, consumption and conception of social space. There are seemingly infinite possibilities for rediscovering cultural and media artifacts; we can mashup and remix them in new forms to shape the culture, discourse and space. Thanks to the proliferation of devices able to capture and instantly share "samples" and recordings of both physical and digital artifacts, alongside the availability of vast amounts of material online to be mined and remixed, it is possible to actively engage in shaping social spaces both online and offline.

In his seminal 1974 book, The Production of Space, Henry Lefebvre emphasized space as a consequence and a manifestation of social relationships. ${ }^{4}$ For Lefebvre, under capitalism, space is a product and an economic offering, likened to any other type of merchandise. The Internet, and the spaces it produces (web, social media, online games) can be rearticulated as the spatial "fix"5 "discovered" and produced by capital, another kind of social space.

Online social spaces, structured by their interfaces, are inherently reliant on remix culture working, user generated content, fan and mod cultures' creative production. In a similar way, offline, social spaces - framed and structured by architectural and urban spaces - rely on collective social activity and its creative output. Today cities are being increasingly penetrated by digital technology in various forms of smart computing systems. As physical space is being "enchanted" and "animated" by digital technology and the Internet, one might imagine that the remix culture of online sociality would enter the physical social space.

Today, the city and its parts, in the form of landmarks, individual buildings and streets, can be reconceptualized as multimedia artifacts-in-progress. Enhanced by digital networks and overlays, from smart grids to smartphones, CCTVs and RFIDs, large media screens and notification pings, the space of the city and architecture is largely constructed and experienced with (and through) digital media and remix culture. Sidewalks become part of a game map, a coffee shop becomes a lecture hall, and a garden turns out to be a Pokémon training spot. Fragmenting the experience of physical social space, this blend articulates new forms of hybrid social space, which exist both online and offline.

On the user level, the experience of the city and social space is penetrated by a multiplicity of digital overlays that structure and organize the experience of the space. On the level of urban design and planning, new layers of the city are discovered as more data is mined from it. Seemingly infinite numbers of new spaces are produced by new overlays and more granular data to be captured for 
financial extraction. Remix, then, stitching together social media and physical space, can be seen as complicit in the status quo, as it continues to be instrumentalized to produce new spatial "fixes."

\section{REMIXING LANGUAGE AND SPACE}

The Internet imaginary was constituted through the concepts of physical space-from digital frontier to homepage, domain, portal, website, cyberspace, creative commons. The Internet was compared to a library and to a "coffee shop with a thousand rooms." From Geocities to LambdaMOO to three-dimensional virtual worlds, the aesthetics and the vision of the Internet have been informed by the experience of physical social space and the city. ${ }^{6}$ Terms such as virtual frontier, terra nova, Great New World proliferated in the early days of the Internet: from science fiction imagination in William Gibson's Neuromancer, ${ }^{7}$ to Autodesk's John Walker and "new worlds" of cyberspace. ${ }^{8}$ In 1996, John Perry Barlow in a Declaration of the Independence of Cyberspace situated cyberspace as a "global social space," a new uncharted territory that is beyond the reach of borders that outline any nation-state's sovereignty. ${ }^{9}$ In 1996 , William Mitchell in his City of Bits argued that Internet networks are as valuable for urban life as street systems; memory and screen space online and on a personal computing device are akin to real estate. ${ }^{10}$

The Internet as an entity has no singular, manifest representation. Unlike other infrastructures that might have a seeming visual and structural clarity, e.g., transportation or telecommunications, there is no singular material entity that can clearly signify the Internet. Thus, fragmented networks of different devices and actors become singular entities via a spatial metaphor. The metaphors not only imagine but also "explain" the Internet, serve as rhetorical devices, and overcome its multidimensional incoherence and lack of form.

Spatial metaphors used to describe the Internet influence its development and play a role in normalization and validation of certain values. There is a fundamental difference between the social, collective space metaphors of the Internet such as coffee shop or library versus the "information superhighway" which emphasizes the private use of the Internet (akin to a personal automobile) rather than its capacity to structure and facilitate social groupings. ${ }^{11}$ With this metaphor the potential of human communication and the social capacity of the Internet seem to be neglected in favor of its everyday utility.

From the user experience standpoint, the lack of the familiar attributes of offline social spaceactual physical space, embodied navigation, optical experience, sensory immersion-forced the early web to be dependent on spatial metaphors. Effective metaphors can be pervasive and through perpetual reproduction, circulation and refinement they can become a crucial part of language and thought.

This reliance on metaphors has the capacity to obfuscate complex relationships between technology, space and society. Facebook, for instance, utilizes friendship as a metaphor for any social connection. Twitter is said to be a "global town square" where anyone can express themselves and be heard. The question remains, what are the distinctions between a physical coffeeshop and the Internet-as-coffee-shop, in relation to the issues of access, usability, social interaction and economic and power relationship? Moreover, these metaphors bring with them the detrimental features of physical social spaces, their power dynamics and struggles. 
In a reciprocal movement, technological solutions in the physical social space now come hand in hand with metaphors inherited from the Internet and software imaginary, ${ }^{12}$ such as participatory web, Web 2.0, and "perpetual beta." The city is imagined as infinite cyberspace, connected, seamless and crowdsourced. Paper-based maps are replaced by perpetually updated digital maps, GPS navigation systems and satellite images that render themselves as objective truths. Ubiquitous sensors, CCTV systems and tracking devices on personal smartphones render and condition a particular experience of the city and the social space. As physical social space has become increasingly layered, managed, produced and mediated by digital and Internet-enabled technologies, the metaphors from digital technology have come to pervade the urban imaginary. The capital explosion of space reinvents and re-"discovers" the physical space of the city anew through its reorganization (reproduction, repetition, remix) with and via digital technology.

The cumulative idea of the Internet and Internet culture is a body of multiple heterogeneous concepts, often made in opposition, rhetorical devices and ideologies: from openness to the oppression of democracy, materiality and immateriality, subversion of capital and a manifestation of hypercapitalism. Nonetheless, the particular vision of the Internet as an open, flexible and friction-free environment, coupled with the ideas of participation and collectivism (or collective intelligence) has been widely applied in relation to the physical space of tech-fueled urbanization. Broadly, the city is being rebranded as a "platform."

In 2016, Dan Doctoroff, CEO of Sidewalk Labs, an urban tech branch of Alphabet, laid the conceptual groundwork for the Quayside Project in Toronto, by exemplifying the ambition to "build cities from the Internet up" and by that to replicate the capacity of the Internet to be a petri dish for innovation, cultural production and participation within the physical city. ${ }^{13}$ Comparing the social dynamics of the future city to Web 2.0, this vision situated itself in opposition to a "topdown" urban planning approach in favor of laying "foundations [to] let people create [the city] on top of it." Further, Doctoroff painted a picture of a city, which through a "flexible physical layer" and "adaptable software" would "empower people to build and change 'applications' much faster than is possible in cities today." "The city becomes a prototype and a "living laboratory for urban technology - a place to explore coordinated solutions, showcase innovations, and establish models for others to follow." "15

This vision of the city as an ever-changing living laboratory is reminiscent of the concept in software development called "the perpetual beta," referring to software released unfinished or with untested features. The perpetual beta implies the continuous improvement of a system, in which updates and new features are released based on collective intelligence or feedback. Tim O'Reilly, the software developer who coined another term, Web 2.0, emphasizes the importance of the participation of users in the process as co-developers, analogous to open-source development practices. ${ }^{16}$ Yet tech corporations often launch beta-versions to see what sticks with consumersimperfect software releases can cut costs of development and optimize the product for profits. Users branded as "co-creators" participate in unpaid digital labor, ${ }^{17}$ and the proprietary software gets better.

The urban metaphors inherited from the Internet imaginary turn out to be instructive calls for action and thought. Inherited from the web and closely related to remix culture, the digital metaphors utilized to describe the city today dilute the city and its embodied materiality and friction. They run the risk of negating the materiality of the urban and architectural space, which can have a utopian 
potential for emancipatory change without restructuring via digital technology. This is where the ubiquity and seemingly infinite possibilities of remix lend themselves to the further fragmentation of the social space and perpetuate its endless reinvention without the use of its emancipatory potential.

\section{CROWDSOURCING SOCIAL SPACE}

The confusion between individual expression and free-market capitalism has been haunting the world at least since postmodernism. In the mid-century, the authorial modernist figure of an architect and the state, as the primary actors of urban design, have been gradually replaced by corporate and commercial development. The top-down state-driven and expert-knows-better planning and Bauhaus "total architecture"18 or "total design"19 aiming toward reformation of the social order was supposedly replaced by a more "pluralistic approach" aiming to incorporate more actors in the design and planning process. Modernist megastructures and the totality of an urban master plan were set aside in favor of the Non-Plan City, ${ }^{20}$ Collage-City, ${ }^{21}$ and strip mall. Large scale modernist social projects aiming to reform the social sphere were replaced by capital-driven spaces to both consume and to convene.

If in modernism the state is the primary decision-making subject in the construction of the built environment and social sphere, in postmodernism it is the commercial developer; contemporary smart city movement heralds the tech companies not only as infrastructure providers, but as developers, managers and operators, major stakeholders of space. Throughout the last couple of decades, IBM, Cisco, Siemens and Alphabet have been launching massive campaigns to reenvision themselves as key stakeholders and decision-makers in urban development. IBM and Cisco, for instance, privately or through the formation of public-private partnerships, have been developing and implementing a broad range of programs and proposals for new and existing cities to utilize their proprietary products and technologies as crucial urban and civic infrastructures. ${ }^{22}$

The language and the visions of the city as a computable, calculable complex system have long permeated the city imagination. These imaginations combined with collective participation and expression are not original with smart city proponents and can be traced to radical post-war architecture and planning projects. Cybernetic visions and architecture of information has inspired the imagination of post-war architects. For example, Cedric Price and Joan Littlewood in Fun Palace envisioned architectural and urban space which combined the ideas of cybernetics, game theory, information technology, theater and Situationism. With unspecified program and indeterminate form, Fun Palace was imagined to be constantly adaptable to the needs of its users. ${ }^{23}$ Developed in the 1960s, Fun Palace can be regarded as a prototype for responsive architecture, in which spaces reconfigure in accordance with the collective needs of the inhabitants. Designed in collaboration with Gordon Pask, the early cyberneticist, Fun Palace's ever-changing structure was determined by the flows of information accessed not via direct input of the users, but through data collection via sensors. The data would be compiled to establish trends, which would set the parameters for the modification of spaces and activities in Fun Palace. The walls would move in response. $^{24}$

Earlier examples of Smart Cities, such as New Songdo in South Korea, resonate with this approach. As Christine Rosen writes, "Songdo claims intelligence not from its inhabitants, but from the millions of wireless sensors and microcomputers embedded in surfaces and objects throughout the 
metropolis." 25 The city was built from scratch on reclaimed land and is dubbed the biggest private real estate development in the world. ${ }^{26}$ The spatial layout of the city is reminiscent of exemplary modernist urban planning with technocratic administration, with its clear and legible layout, wide automobile streets and residential towers surrounded by calculated green surface areas. Smart appliances are installed in every home, trash is moved via pneumatic tubes, moving and stationary sensors (in cars and on the streets) measure the flow of traffic and people. All data is congregated on display in the Cold War-style command and control room. Yet Orit Halpern remarks that in these control rooms, humans are only passive observers, as for the most part the systems run themselves. ${ }^{27}$

While such an approach to the Smart City — built from scratch, centralized, large - is criticized by the media and academia, ${ }^{28}$ the rhetoric of smart cities has been adjusted towards smart citizens. In light of debates concerning data privacy, and the unprecedented power given to the tech corporations by governments to virtually create, run and de facto own the cities, the discourse has shifted from technology towards technologically driven citizen participation. A vision for participation, inherited from the web and associated with Web 2.0, found its home in the smart city concept, which does not require significant technological advancement, but focuses on citizen participation in decision-making pertaining to the built environment. Not unlike Web 2.0, which has emerged, arguably, accidentally through the collective social practices of content creation and exchange, the city of smart citizens is portrayed as depending on collective intelligence and sharing on the city scale, accelerated with digital technology. Here citizen participation in urban governance is conceptualized and branded as co-creation and co-production. Equipped with communication and computing devices, citizens transform from passive subjects to active actors who demand more participatory and transparent processes.

This concept found its place through online platforms, events or smart citizen programs and kits that connect city government, citizens, developers and others in pursuit of improvement of urban policies and projects. However, as Jathan Sadowski reveals, in Smart City rhetoric the term "public engagement" is often used as a proxy for "public relations" and rarely translates into the change of the project in question. ${ }^{29}$

From the governance perspective, while citizen science and smart citizen practices allegedly raise awareness, educate and strengthen the community, ${ }^{30}$ these practices are simultaneously motivated to cut municipal costs and to serve as an instrument that increases trust in the government. Zandbergen and Uitermark in their study of the citizen science initiative Smart Citizen Kit in Amsterdam reveal that from the perspective of the participating citizens, the kit was expected to generate data on air pollution levels that would have the capacity to bring policy transformations. Yet in fact, the data that the kits could collect was not sufficient. Besides, several existing municipal measurement networks available to the public could provide substantially more detailed information on the city's air quality. This example illustrates a different type of citizenship, which Zandbergen and Uitermark call "cybernetic citizenship," in which citizen data collection is no longer an advocacy tool, but a tool for decentralized and individual engagement with the environment. The participants of Smart Citizen Kit experiments have been referred to as first explorers of the uncharted territory of "new ways of making sense of one's own environment." Thus, the practice of sampling the reality actualized with the kit is an act of individual empowerment. 
The emergence of the subject of the smart citizen blurs the distinction between democratic participation and the availability of technological instruments, and it represents the city-as-aservice by rendering it as an apolitical entity. ${ }^{31}$ As Cardullo and Kitchin suggest, these "citizencentric" smart city initiatives prioritize market-led solutions to urban issues rather than being grounded in civil rights and the common good. ${ }^{32}$ The term citizen is used as an empty signifier, and the concept of citizenship is reduced to the ability to make a consumer choice, selecting from the offered services and providers.

Social media platforms, from Facebook to TikTok, utilize the collective intelligence of their users to generate value. On the one hand, remix culture of the social media platforms is subversive by definition, as it challenges the former relationship between professional and amateur, culture industry and audience, and complicates the concept of intellectual property. On the other hand, this very culture is appropriated by big tech with the Web 2.0 business model that generates value from user interactions, user-generated content and user data. Obscuring the power structures of platform capitalism, the Web 2.0 rhetoric has added to the idea of the Internet as the "open and frictionless frontier" an image of collectivity and sociality. ${ }^{33}$ Equating individual expression with corporate deregulation, the Internet has translated these values to the urban space through the metaphor of the city as an empowering and participatory space, equipped with devices that foster awareness and collective action.

To paraphrase Henry Jenkins, participatory culture is culture with relatively low barriers to civic engagement, and it relies on strong informal ties and mentorship. ${ }^{34}$ None of it seems to be true in relationship to the smart city and smart citizen projects and proposals. Web 2.0 is a set of corporate tools designed to capture and exploit participatory culture. The adoption of Web 2.0 rhetoric by the urban space results in a system in which the company provides a city-as-a-service. This approach leaves unnoticed serious urban issues such as inequality or pervasive discrimination and focuses instead on those aspects that can bring revenue. If only we could unsubscribe from the city as easily as we can from Netflix.

\section{REMIX AND IMAGES OF SPACE}

Mechanical recording opened the possibility to sample and capture reality. From the daguerreotype of the 1830 s to photography and video- and audio-recording, mechanical reproduction has become a crucial part of cultural production. With mechanical recording, architecture is built not only to be seen, but to be captured, disseminated and post-processed. Further, postmodernism continued the trend of sampling reality; it started collaging these samples into new objects. Today, with the proliferation of digital technology, cultural software and the spectrum of capturing devices, these processes - of sampling and capturing and remixing - have dramatically increased in scale and relevance to the shaping of space.

Spaces - urban, architectural, everyday spaces and environments - are produced by design methods that inherently utilize remix practices. Remixing, the appropriating of existing cultural tropes and architectural forms to produce new meaning, has taken place in many instances in architectural practice. The space of Romanesque and Medieval cathedrals used to be read as a book, their walls, stained glass windows, paintings and mosaics contained religious narratives and instructed rituals and processions. From revivalist movements to postmodern architecture flirting with the formal characteristics of the architectural canon, cultural adoption has been an essential 
aspect of architectural practice. As Venturi and Scott Brown have argued, even modernist architecture, which is supposedly non-referential and non-symbolic, indulged in the fetishizing of industrial forms and in using them as pure formal symbols with no function following. ${ }^{35}$

From the perspective of aesthetics, postmodern architecture and urbanism allowed play, irony, and subversive sampling of meaning to enter the production of space. Moreover, postmodernism treats the history of architecture as an archive of symbols to be mined, manipulated and rearranged in new forms. The building is a "duck" or a "decorated shed"; it is an icon or has icons on it. ${ }^{36}$ Las Vegas, the city celebrated by Venturi and Scott Brown, had become an ultimate collage of heterogeneous private developments and expressions of popular culture symbols. Inherently subversive, Learning from Las Vegas was an act of resistance to the status quo - the pop culture and everyday spatial reality and lived experience juxtaposed with the siloed world of architectural and planning elites. The idea of architecture and the urban space as collage-like also coincided with the use of collage as a representation technique in architectural practice.

Collage as a method of architectural representation first went mainstream in the 1960s, with the aforementioned radical architecture groups. Archigram, a radical architecture group influenced by pop culture, began using collage to create representations of their speculative proposals. Combining images and text cutouts from different media, they aimed to be playful and subversive as well as more accessible and exciting to the general public. With their concept of Continuous Monument, Superstudio, a Florentine radical architecture group, offered the critique of both modernism and consumerism. Continuous Monument is a series of collages that represent large-scale volumes of megastructures infinitely embracing the planet. As an exaggerated parody of the modern architecture of anonymous steel and glass boxes, and simultaneously an anti-design response to the kitsch mass culture aesthetics, this project is both a mockery and a validation of the phenomena criticized.

With these groups, collage was used as a form of resistance to the conventional means of architectural representation, and as a tool to capture the complex and splintering social order and culture. Today, on the other hand, collage is regarded as a conventional architectural visualization technique, widely utilized in all aspects of practice. Moreover, if an analog collage implied a clash or juxtaposition of elements, a digital collage allows for a seamless blend of different parts. Instead of revealing the dis-contingency and disjointedness inherent to collage, contemporary digital collage representing architectural space strives to be seamless and smooth, with all elements within the image having similar shading, harmoniously composed proportions and tone.

Today, most architectural images are digital artifacts. Digital tools such as CADx and visualization software have become the primary means for the design process and the representation of architectural projects. The software used in architectural practice not only rearticulates ways the built environment is conceived of and represented in the form of images, but also changes the meaning and role of the images in the practice. With Building Information Modeling software, such as Autodesk Revit for example, the design process expands to embrace database management and translation between digital formats. The broad variety of software tools utilized in architectural practice from Photoshop to 3Ds Max to Revit produce the culture of architectural production and are in turn shaped by the culture. 
Architects do not make buildings; they make drawings of buildings. To paraphrase Robin Evans, unlike sculptors or painters, architects never work with the object of their thought. ${ }^{37}$ Working through a medium, whether it is a collage, digital visualization or orthographic projection, architects have to learn how to suspend critical disbelief and to translate between drawing and building. Such displacement posits the question, using Evans's distinction, of the relationship between drawings and buildings, or between images and spaces. Thus, architectural images oscillate between their purpose as an indexical link to an architectural project and as their autonomous role as an artwork.

Mixing collage, rendering and what Lev Manovich calls "digital painting," 38 architects produce images of buildings that might possibly exist in the future. The human figures around the building in the image are sourced from famous art from Hockney to Rousseau, or online collections of PNG cutouts ranging from photographs to monotone silhouettes in vector formats. Later, these images serve as sampling materials to produce more images, or as points of reference in the production of new images. With 3D rendering, architects simulate the sun, sky, sourced online textures and materials in the infinite cartesian space of Rhino, 3Ds Max, Maya or Blender. "In design worlds, the architect decides where the sun goes." 39

In architecture, images depict possible futures: they are illustrations of what the building or a city might look like before any construction has started. An architectural rendering-whether it is a photorealistic image or a stylized one - is often regarded as a rhetorical device, a tool to lure the client or the public into the approval (or rejection) of the project. Widely different images and visualizations are used for public discussions, investors, press or exhibitions.

The software used in architectural practice, whether it is 2D, 3D or BIM, allows for the further compartmentalization of the fragments, for the dissection and swapping of their aspects. Any texture can be assigned to any object, and a brick wall can bend if needed. The scale of certain objects in the image can be increased to make the whole relative space look smaller. Manipulations with the camera lens can make space look larger or smaller, depending on the desired effect of the image. Color-correction can turn dullness into mystery; cutout trees can hide a boring facade. ${ }^{40}$ This malleability of architectural image manipulates the perception and can obfuscate the reality of the space. The images become a spectacle, preceding the possible construction, and often have a tangential relationship with the finished building.

With the popularization of the discourse on sustainability in architecture that began in early 2010 , green facades and "bushy" skyscrapers with luscious plants on every balcony have become an architectural rendering staple and a go-to architecture for a pitch or a competition. Wide public appeal of so-called green architecture helps with the funding and marketing. Nonetheless, there are no successful real-life examples of such green facades beyond the images. This "digital greenwashing" is often associated with claims of sustainability and serves to obscure the construction's ecological impact. ${ }^{41}$

Some real estate listings with architectural visualizations are indiscernible from photographs. As with digital images in post-production, the images produced for real estate - both photographs and photo-real renderings - are nothing more than a special kind of painting, where reality has been manipulated and commodified. For instance, RoOomy, a company specializing in digital staging, 
works with real estate brokers and home furnishing retailers to digitally enhance a property. Their service includes digital furnishing (incorporation of photorealistic furniture into a photograph of an empty interior), converting 2D images of the interiors into 3D models to design "virtual walkthroughs," and custom augmented reality interior design applications. ${ }^{39}$ Here the photograph — a sample of reality — serves as raw material to be transformed into a sales pitch.

As Orit Halpern notices in the context of smart city visualizations, the images lose their indexical relationship with reality to be a "concealing spectacle," 42 and become what Rem Koolhaas called "junkspace"-generic and amorphous, indifferent, with all elements replaceable and interchangeable. ${ }^{43}$ However, while the architectural rendering is not evidence of any objective truth, it has the capacity to redefine our basic understanding of the world, from sustainability, public space, domesticity, to the totality of the planet. Utilizing the remix techniques inherent in the cultural software actively used in architectural practice and discipline, images operate as rhetorical devices aimed at enclosing the space and converting it into a tool to generate economic value.

\section{SOCIAL REMIX}

Beyond cultural software used in architectural design practices, social media have become a pervasive tool to sample, disseminate and transform the images of space. When online social space overlaps with architectural social spaces, they seem to alter and affect each other in profound ways. The physical social space, sampled as an image, is transformed. In this context, architectural and urban spaces become raw material for the production of visual content on social media. In a reciprocal movement, phenomena that are constitutive of contemporary digital remix culture, such as crowdsourcing, user generated content and collective collaboration have penetrated ways we think of physical social space.

In 2014, the London-based architectural collective Assemble Studio made a DIY shed in the yard by their office. Conceived as a model of an affordable workplace for designers and artists, the facade wall of Yardhouse was decorated with diamond-shaped multicolored shingles. Unknowingly, the architects had made a wall that checked all the boxes to be a perfect Instagram backdrop. It became so popular on social media that even though the building itself has been dismantled and the famous tiles put into storage, the pastel pattern continues to replicate itself and exist as unofficial merchandise, product packaging or digital stock images. There are phone cases, blankets, suitcases, desktop wallpaper and even elements of beauty product packaging generated from photographs of the famous Yardhouse wall.

This transformation of the pastel shingle wall texture into a global photo destination, eventually outliving the actual physical wall as a media object, is akin to "media mobility," described by Manovich as when "a message (an image) continues to move between sites, people, and devices. As it moves, it accumulates comments and discussions. Frequently, its parts are extracted and remixed with parts of other messages to create new messages." 44 Consequent actions - embedding, reposting, sharing, downloading and so on-are enabled by social media interfaces, contributing to the process of remixing the original cultural artifact into new media objects. Yardhouse wall becomes a cultural phenomenon that is enabled by media mobility. ${ }^{45}$

Jacques Attali in Noise: The Political Economy of Music states that an act of going to a live musical performance implies a deliberate commitment of being in a social space. ${ }^{46}$ Attali speaks of the 
repetition (musical recording) subverting and challenging the act of representation (live performance), which consequently changes the social aspects of the musical experience. ${ }^{47}$ As performance becomes auxiliary to recording, it is a simulacrum thereof. Further, recording of music and the fragmentation of social space of music becomes a precondition to composition, both musical and social. Composition, as loosely defined by Attali, is a "self-communication, ... something fundamentally outside all communication, a solitary, noncommercial act." "48 Yet while Attali emphasizes the individualistic nature of composition (as an act of production and distribution of music), it is seen as a necessarily collective process: "To express oneself is to create a code, or to plug into a code in the process of being elaborated by the other." ${ }^{49}$ Attali's composition seems to bear certain resemblance to remix culture, as it has the capacity to produce a different kind of social relations and a collective creative practice.

A similar trajectory can be seen in regard to production of visual media on such platforms as Instagram and Pinterest. Yardhouse, therefore, becomes a photo destination because of its growing persistence and popularity in the online social space. The social and cultural value of Yardhouse as a photo backdrop seems to supersede its value as a pilot of an affordable workshop. On the other hand, most of the people who know of this space have seen it online, on Instagram or Pinterest, and never visited it in London. Their experience of Yardhouse as a media object is structured by social media interface and temporary hype around its visual qualities so well suited to social media. Thus, online social space actively shaped the cultural image and the experience of Yardhouse.

The transformation of physical space into a media object sampled from the physical space, and its consequent alteration through online sociality, effectively transforms the ways the physical social space is perceived, conceived of and lived. Beyond the depictions of space within architectural discourse, the space is digitally (re)produced with social media. Instagram, Pinterest, Airbnb and other "visually inclined" platforms further complicate the relationship between lived space and digital images. The collective effort of millions of users produces cultural trends and expectations, by which image-commodities absorb the built environment and the social space.

Susan Sontag in On Photography wrote that photography is the act of capturing reality to own the moment. By taking pictures, people collect objects and spaces - not the photographs, these pieces of paper or arrays of pixel data, but the things, the objects that they "sample" from the world in the form of visual media. ${ }^{50}$ Roland Barthes adds that photography, as a recording, captures the moment in time that can be "relived" later on. ${ }^{51}$ Kodak moments are an occasion, suitable to be memorized in the form of a photograph. Photography becomes evidence that the occasion indeed happened. With digital photography, samples of things and of moments, collected and organized to be relived are edited and post-processed. With social media, they are also shared with the world.

Recorded, sampled and post-processed reality has become the primary form of experience in everyday life. The images we consume shape the vision and the narrative of the world we live in. No longer is travel needed to experience wonder, sublime and uncanny spaces, it can be done from the comfort of the computer at home. As more and more media utilize CGI technologies, and thereby distort the environments on display, they more directly shape the cultural context. These media and perfected images become measures for imperfect reality.

On the other hand, the purpose of travel and movement is no longer the actual experience of space, but its capture in the form of visual content, a photograph or a video. The sampling of reality seems 
to become more relevant than its embodied experience. Yardhouse was located in London's Stratford, very much off the typical tourist track. The only reason for tourists or local Londoners to come there, it seems, would be to have their Instagram moment. The quality of the craftsmanship, the design, and the purpose of the building itself seem to be secondary to the wall's role in the form of digital image.

While the scale and scope of cultural production have been growing exponentially, the collective effort of the billions of users sharing content daily has produced a lived space of images that have a nuanced relationship with the gritty reality. Lev Manovich in his work and research on Instagram stretches the embeddedness of the image cultures that develop around technological media into the particular systems of production and aesthetic conventions (whether endorsed by the users or marketed by the platforms). ${ }^{52}$ These conventions in response redefine the relationship between images and space. As the world is increasingly experienced through digital screens, the world itself - overpowered by image-driven experience — has (in reverse) begun imitating the images.

As the platforms perpetually change during their lifespan through software updates (perpetual beta), so the cultural trends and their "visual language" are changing. New features in Instagram, for example, include instant messaging, business accounts, stories, insights and archive. These features define what is possible within the platform, and in this way they define and condition the user. These features-like, comment, share, save, archive, add to your story-actively shape the discourse and the aesthetics of the images and therefore the spaces.

Further, put in the broader social context, digital image aesthetics are in relationship with broader cultural trends, popular filters, industry-standard image-processing algorithms and so on. ${ }^{53}$ The media and tools used to produce digital images influence the objects they sample. Today architects are asked to design instagrammable architectures, and whole buildings and neighborhoods are being styled for Instagram. ${ }^{54}$

A number of architectural practices have admitted that they consider "Instagrammability" to be an important aspect of their projects and that they are being asked by clients to design Instagrammable moments. Buildings and public spaces are designed as "selfie sets." Often, the low-cost spectacle leads to low-quality materials that can be post-produced and filtered to look appealing on social media but perhaps lack a utility that extends beyond their use as images. Tom Wilkinson stated in his harsh criticism of architectural photography, "Trash turns into tinsel and muddy water into limpid streams via the refracting crystal of the lens." 55 When space is constructed specifically to be disseminated as a digital image on social media, certain features are favored over others, and spectacle is at risk of overpowering the quality of the experience and capacity of space to become a territory for social encounter and activity.

Disseminated by social media, the images produce a particular kind and vision of social space. Individually, each image produces a captured sample of reality, always post-processed and framed in a certain way. Reality is expected to corroborate the image. As in the case of smart citizens, reality is modulated after its digital shadow: buildings after images and cities after platforms. 


\section{CONCLUSION}

Both online and offline social spaces and their hybrids - smart cities, digital twins and other technospatio-social systems - have been utilizing the metaphors pertaining to the Internet and social and cultural practices emerging online. Simultaneously, with graphic software and the sampling of reality via digital tools, space is constructed through remix as a method of cultural production and design.

While it camouflages the power structures embedded within social systems, and to an extent is coopted for the spatial "fix," remix can also be reframed as a political strategy that has the capacity to disrupt or unsettle the status quo.

The City in the Age of Remix, as we have seen it, has been a reiteration of inherited power structures and political configurations. Its language relies on determinate, clear, discrete boundaries of users, flows and objects, while making an apparently seamless continuity of experience and smooth space. Yet as Benjamin Bratton indicates in The Stack, ${ }^{56}$ the adjacency, overlaying, cross-hatching of sovereignties has long since superseded discernable, sensible or comprehensible boundaries and delineation in space.

Online social spaces have proved to be powerful grounds for the reimagination of the world, disrupting the normalized use of space and social activity. While this essay focuses on the existing uses of remix as a method of spatial production that is often appropriated for the spatial "fix," the hints for the alternative may lie in the method itself. Remix culture is seen to have a subversive potential, as it challenges the former relationship between professional and amateur, culture industry and audience, and it can produce new meaning via modularity, cross-breeding and hybridization of social space. Instead of a typical technocratic narrative of hybrid physical-digital social space, remix as a practice of digital activism could help to reconceive the politics of space.

\section{ENDNOTES}

1. Lev Manovich, "Remix Strategies in Social Media," in The Routledge Companion to Remix Studies, eds. Eduardo Navas, Owen Gallagher, and xtine burrough (Routledge, 2015), 135-54. 2. Brent D. Ryan, The Largest Art: A Measured Manifesto for a Plural Urbanism (Cambridge, MA: MIT Press, 2017).

3. Cecilia D'Anastasio, "Games Like Fortnite Are Today's 'Third Places," Wired, April 2020, accessed August 1, 2020, https://www.wired.com/story/fortnite-travis-scott-party-royale-thirdplace/.

4. Henri Lefebvre, The Production of Space (Oxford: Basil Blackwell, 1991). 
5. David Harvey, "Globalization and the 'Spatial Fix,"' in Marxism in Geography (geographische revue, 2001); David Harvey, Spaces of Capital: Towards a Critical Geography (Hoboken: Taylor and Francis, 2012).

6. Stephen Graham, "The End of Geography or the Explosion of Place? Conceptualizing Space,

Place and Information Technology," Progress in Human Geography, July 1, 2016,

https://doi.org/10.1191/030913298671334137.

7. William Gibson, Neuromancer (London: HarperCollins, 2001).

8. John Walker, "Through the Looking Glass," accessed June 12, 2020,

https://www.fourmilab.ch/autofile/e5/chapter2_69.html.

9. John Perry Barlow, "A Declaration of the Independence of Cyberspace." Electronic Frontier

Foundation, January 20, 2016. https://www.eff.org/cyberspace-independence.

10. W. J. Mitchell, City of Bits: Space, Place, and the Inforbahn (Cambridge, MA: MIT Press, 1996).

11. Martin Dodge, "Understanding Cyberspace Cartographies: A Critical Analysis of Internet Infrastructure Mapping” (ProQuest, 2008).

12. Rob Kitchin and Sung-Yueh Perng, Code and the City (London: Routledge, 2016).

13. Doctoroff, Daniel L. "Reimagining Cities from the Internet Up," Medium, December 12, 2016. https://medium.com/sidewalk-talk/reimagining-cities-from-the-internet-up-5923d6be63ba.

While Sidewalk Labs no longer pursues Quayside Toronto, the rhetoric and the use of the Internet metaphors to describe the future of the smart neighborhood continues to shape the conversation about the future of cities.

14. Ibid.

15. Ibid.

16. Tim O’Reilly, “What Is Web 2.0?,” accessed June 12, 2020.

https://www.oreilly.com/pub/a/web2/archive/what-is-web-20.html.

17. Term coined by Tiziana Terranova. See Tiziana Terranova, "Free Labor: Producing Culture

for the Digital Economy," Social Text, 63 (vol. 18, no. 2), Summer 2000, 33-58.

18. Walter Gropius, Scope of Total Architecture (New York: Collier Books, 1974),

http://catalog.hathitrust.org/api/volumes/oclc/9950478.html.

19. Mark Wigley, "Whatever Happened to Total Design?," Harvard Design Magazine: Design

Arts and Architecture, no. 5 (1998), http://www.harvarddesignmagazine.org/issues/5/whateverhappened-to-total-design.

20. New Society, special issue with "Non-Plan: An Experiment in Freedom," March 20, 1969.

21. Colin Rowe and Fred Koetter, Collage City (Basel: Birkhäuser, 2009).

22. Ola Söderström, Till Paasche, and Francisco Klauser, "Smart Cities as Corporate

Storytelling," City 18, no. 3 (May 4, 2014): 307-20.

23. Stanley Mathews, "The Fun Palace as Virtual Architecture: Cedric Price and the Practices of Indeterminacy." Journal of Architectural Education 59, no. 3 (February 2006): 39-48.

https://doi.org/10.1111/j.1531-314X.2006.00032.x.

24. Ibid.

25. Christine Rosen, "The Machine and the Ghost," The New Republic, July 12, 2012, https://newrepublic.com/article/104874/rosen-verbeek-technology-morality-intelligence.

26. "PROJECT FINANCE" Site Selection Magazine, January 2008," accessed November 1, 2020, https://siteselection.com/issues/2008/jan/projectFinance/.

27. Orit Halpern, Beautiful Data: A History of Vision and Reason since 1945 (Durham, NC: Duke Univ. Press, 2014).

28. Adam Greenfield, Against the Smart City (New York City: Do projects, 2013). 
29. Ibid.

30. Dorien Zandbergen and Justus Uitermark, "In Search of the Smart Citizen: Republican and Cybernetic Citizenship in the Smart City," Urban Studies 57, no. 8 (June 2020): 1733-48, https://doi.org/10.1177/0042098019847410.

31. Ibid.

32. Paolo Cardullo and Rob Kitchin, "Being a 'Citizen' in the Smart City: Up and Down the Scaffold of Smart Citizen Participation," SocArXiv (Center for Open Science, May 15, 2017), https://ideas.repec.org/p/osf/socarx/v24jn.html.

33. For the term platform capitalism see Nick Srnicek, Platform Capitalism, (Cambridge, UK: Polity, 2018).

34. Henry Jenkins, "Why Participatory Culture Is Not Web 2.0: Some Basic Distinctions," accessed June 17, 2020,

http://henryjenkins.org/blog/2010/05/why participatory culture is n.html.

35. Robert Venturi, Denise Scott Brown, and Steven Izenour, Learning from Las Vegas,

(Cambridge, MA: MIT Press, 2017).

36. Ibid.

37. Robin Evans, Translations from Drawing to Building and Other Essays, 1st edition

(Cambridge, MA: The MIT Press, 1997).

38. Lev Manovich. "What is Digital Cinema?," http://manovich.net/index.php/projects/what-isdigital-cinema.

39. Susan Piedmont-Palladino, "Into the Uncanny Valley," Places Journal, April 24, 2018, https://doi.org/10.22269/180428.

40. Minkjan Mark, "What This MVRDV Rendering Says about Architecture and the Media,"

Failed Architecture, accessed June 15, 2020, https://failedarchitecture.com/what-this-mvrdv-

rendering-says-about-architecture-and-media/.

41. "Virtual Staging Services | RoOomy.” Accessed June 15, 2020. https://rooomy.com/realestate-virtual-staging-overview.

42. Halpern, Beautiful Data, 239-50.

43. Rem Koolhaas, "Junkspace," October, 2002, 175-90.

44. Manovich, "Remix Strategies in Social Media," in The Routledge Companion to Remix

Studies, eds., Eduardo Navas, Owen Gallagher, and xtine burrough (New York: Routledge, 2015), 135-154.

45. Ibid.

46. Eduardo Navas, Remix Theory: The Aesthetics of Sampling (Vienna: Springer, 2012), 5-6; Jacques Attali, Noise: The Political Economy of Music (Minneapolis: University of Minnesota, 2014), 31 .

47. Ibid, 85 .

48. Ibid, 32 .

49. Ibid, 143.

50. Susan Sontag, On Photography (New York: Picador, 1978).

51. Roland Barthes, Camera Lucida: Reflections on Photography, trans., Richard Howard (New York: Hill and Wang, 2010).

52. Lev Manovich, Instagram and Contemporary Image,

http://manovich.net/index.php/projects/instagram-and-contemporary-image (2017).

53. Ibid, 14. 
54. Bella Mackie, "Is Instagram Changing the Way We Design the World?" The Guardian, July 12, 2018, https:/www.theguardian.com/lifeandstyle/2018/jul/12/ready-for-your-selfie-whypublic-spaces-are-being-insta-designed.

55. Tom Wilkinson, "The Polemical Snapshot: Architectural Photography in the Age of Social Media," Architectural Review, January 15, 2015, https://www.architectural-

review.com/essays/photography/the-polemical-snapshot-architectural-photography-in-the-age-ofsocial-media/8674662.article.

58. Benjamin H Bratton, The Stack: On Software and Sovereignty (Cambridge, MA: The MIT Press, 2016), 32.

\section{REFERENCES}

Attali, Jacques. Noise: The Political Economy of Music. Minneapolis: University of Minnesota, 2014.

Barlow, John Perry. "A Declaration of the Independence of Cyberspace,” Electronic Frontier Foundation. January 20, 2016, https://www.eff.org/cyberspace-independence.

Barthes, Roland. Camera Lucida: Reflections on Photography. Translated by Richard Howard. New York: Hill and Wang, 2010.

Bratton, Benjamin H. The Stack: On Software and Sovereignty. Cambridge, MA: MIT Press, 2016.

Cardullo, Paulo and Rob Kitchin. "Being a 'Citizen' in the Smart City: Up and Down the Scaffold of Smart Citizen Participation.” SocArXiv, SocArXiv. Center for Open Science, May 15, 2017. https://ideas.repec.org/p/osf/socarx/v24jn.html.

D’Anastasio, Cecilia. “Games Like Fortnite Are Today's 'Third Places,"” Wired. 29 April 2020. Accessed June 15, 2020. https://www.wired.com/story/fortnite-travis-scott-party-royalethird-place/.

Doctoroff, Daniel L. "Reimagining Cities from the Internet Up.” Medium, December 12, 2016. https://medium.com/sidewalk-talk/reimagining-cities-from-the-internet-up5923d6be63ba.

Dodge, Martin “Understanding Cyberspace Cartographies: A Critical Analysis of Internet Infrastructure Mapping." ProQuest, 2008.

Evans, Robin. Translations from Drawing to Building and Other Essays, 1st edition. Cambridge, MA: The MIT Press, 1997.

Gibson, William. Neuromancer. London: HarperCollins, 2001. 
Graham, Stephen. "The End of Geography or the Explosion of Place? Conceptualizing Space, Place and Information Technology." Progress in Human Geography. July 1, 2016. https://doi.org/10.1191/030913298671334137.

Greenfield, Adam. Against the Smart City a Pamphlet. This Is Part I of "The City Is Here to Use.” New York City: Do Projects, 2013.

Gropius, Walter. Scope of Total Architecture. New York: Collier Books, 1974.

Halpern, Orit. Beautiful Data: A History of Vision and Reason since 1945. Durham, NC: Duke University Press, 2014.

Harvey, David. "Globalization and the 'Spatial Fix."” In Marxism in Geography (geographische revue, 2001.

—. Spaces of Capital: Towards a Critical Geography. Hoboken: Taylor and Francis, 2012

Jenkins, Henry. "Why Participatory Culture Is Not Web 2.0: Some Basic Distinctions.” Accessed June 17, 2020.

http://henryjenkins.org/blog/2010/05/why_participatory_culture is_n.html.

Kitchin, Rob, and Sung-Yueh Perng, eds. Code and the City. New York: Routledge, 2016.

Koolhaas, Rem. “Junkspace.” October 100, (2002): 175-90.

Lefebvre, Henri. The Production of Space. Oxford: Basil Blackwell, 1991.

Mackie, Bella. "Is Instagram Changing the Way We Design the World?" The Guardian, July 12 , 2018. https:/www.theguardian.com/lifeandstyle/2018/jul/12/ready-for-your-selfie-whypublic-spaces-are-being-insta-designed.

Manovich, Lev. "What is Digital Cinema?," 1995. Accessed November 9, 2020. manovich.net/index.php/projects/what-is-digital-cinema.

- "Remix Strategies in Social Media," in The Routledge Companion to Remix Studies, eds. Eduardo Navas, Owen Gallagher, and xtine burrough. New York: Routledge, 2015.

Mathews, Stanley. "The Fun Palace as Virtual Architecture: Cedric Price and the Practices of Indeterminacy." Journal of Architectural Education 59, no. 3 (February 2006): 39-48. https://doi.org/10.1111/j.1531-314X.2006.00032.x.

Minkjan, Mark. "What This MVRDV Rendering Says about Architecture and the Media," Failed Architecture. https://failedarchitecture.com/what-this-mvrdv-rendering-says-aboutarchitecture-and-media/

Mitchell, William J. City of Bits: Space, Place, and the Inforbahn. Cambridge, MA: MIT Press, 1996.

Navas, Eduardo. Remix Theory: The Aesthetics of Sampling. Vienna: Springer, 2012. 
O'Reilly, Tim. "What Is Web 2.0?" Accessed June 15, 2020.

https://www.oreilly.com/pub/a/web2/archive/what-is-web-20.html

Piedmont-Palladino, Susan. “Into the Uncanny Valley.” Places Journal. April 24, 2018. https://doi.org/10.22269/180428.

Rosen, Christine. "The Machine and the Ghost." The New Republic. July 12, 2012.

https://newrepublic.com/article/104874/rosen-verbeek-technology-morality-intelligence.

Rowe, Colin, and Fred Koetter, Collage City. Basel: Birkhäuser, 2009.

Ryan, Brent, D. The Largest Art : A Measured Manifesto for a Plural Urbanism. Cambridge, MA: MIT Press, 2017.

Sadowski, Jathan. Too Smart: How Digital Capitalism is Extracting Data, Controlling Our Lives, and Taking Over the World. Cambridge, MA: MIT Press, 2020.

Söderström, Ola, Till Paasche, and Francisco Klauser, "Smart Cities as Corporate Storytelling," City 18, no. 3 (May 4, 2014): 307-20, https://doi.org/10.1080/13604813.2014.906716.

Sontag, Susan. On Photography. London: Penguin Books, 1977.

Srnicek, Nick. Platform Capitalism. Malden, MA: Polity, 2017.

Terranova, Tiziana. "Free Labor: Producing Culture for the Digital Economy." Social Text 63 (vol. 18, no. 2), Summer 2000, pp. 33-58.

Venturi, Robert, Denise Scott Brown, and Steven Izenour. Learning from Las Vegas. Facsimile ed. Cambridge, MA: MIT Press, 2017.

Walker, John. "Through the Looking Glass: Beyond 'User Interfaces.” Accessed June 18, 2020. https://www.fourmilab.ch/autofile/e5/chapter2 69.html.

Wigley, Mark. "Whatever Happened to Total Design?" Harvard Design Magazine: Design Arts and Architecture, no. 5. 1998.

Wilkinson, Tom. "The Polemical Snapshot: Architectural Photography in the Age of Social Media." Architectural Review, January 15, 2015, https://www.architecturalreview.com/essays/photography/the-polemical-snapshot-architectural-photography-inthe-age-of-social-media/8674662.article.

Zandbergen, Dorien, and Justus Uitermark. "In Search of the Smart Citizen: Republican and Cybernetic Citizenship in the Smart City." Urban Studies 57, no. 8 (June 2020): 173348. https://doi.org/10.1177/0042098019847410.

\section{AUTHOR BIO}

Alina Nazmeeva is a researcher, architect and artist working with digital media and computer graphics. Alina is a research associate in the future urban collectives lab at MIT, where she works 
on the design of spaces and platforms for new forms of collectivity. She is also a research analyst in the MIT Real Estate Innovation Lab, where she focuses her research on understanding the economy and design of virtual worlds and online games. She studied architecture at Moscow Architecture Institute and was a fellow of the New Normal Program (2017) at Strelka Institute of Media, Architecture and Design. At the MIT School of Architecture and Planning Master's program in Urbanism, her research, artistic work and thesis focused on the intersection of media, technology and the production of space. 